
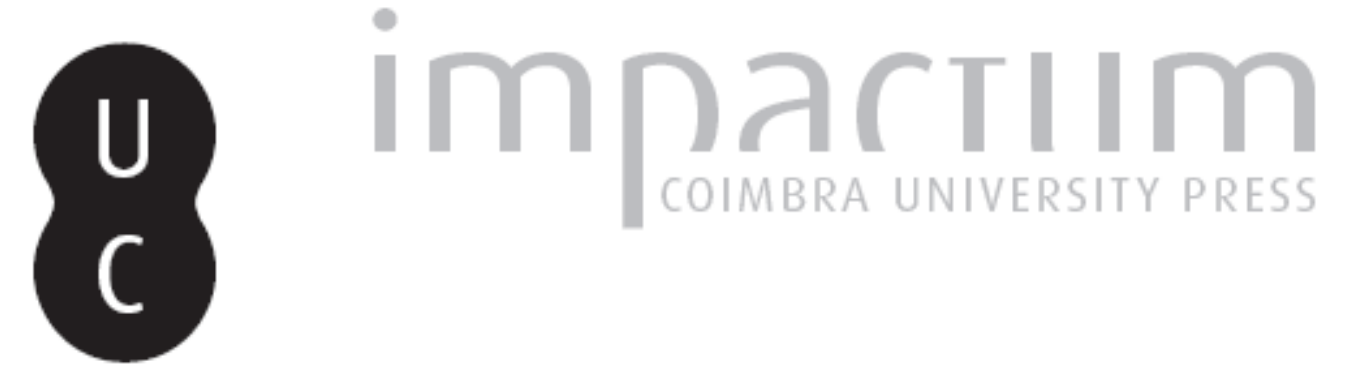

Tacto/contacto: processos de experienciação háptica no corpo cíbrido

Autor(es): $\quad$ Marques, Diogo

Publicado por: Centro de Literatura Portuguesa; Imprensa da Universidade de Coimbra

URL persistente:

URI:http://hdl.handle.net/10316.2/37786

DOI:

DOI:http://dx.doi.org/10.14195/2182-8830_3-1_5

Accessed : $\quad$ 26-Apr-2023 11:14:55

A navegação consulta e descarregamento dos títulos inseridos nas Bibliotecas Digitais UC Digitalis, UC Pombalina e UC Impactum, pressupõem a aceitação plena e sem reservas dos Termos e Condições de Uso destas Bibliotecas Digitais, disponíveis em https://digitalis.uc.pt/pt-pt/termos.

Conforme exposto nos referidos Termos e Condições de Uso, o descarregamento de títulos de acesso restrito requer uma licença válida de autorização devendo o utilizador aceder ao(s) documento(s) a partir de um endereço de IP da instituição detentora da supramencionada licença.

Ao utilizador é apenas permitido o descarregamento para uso pessoal, pelo que o emprego do(s) título(s) descarregado(s) para outro fim, designadamente comercial, carece de autorização do respetivo autor ou editor da obra.

Na medida em que todas as obras da UC Digitalis se encontram protegidas pelo Código do Direito de Autor e Direitos Conexos e demais legislação aplicável, toda a cópia, parcial ou total, deste documento, nos casos em que é legalmente admitida, deverá conter ou fazer-se acompanhar por este aviso. 


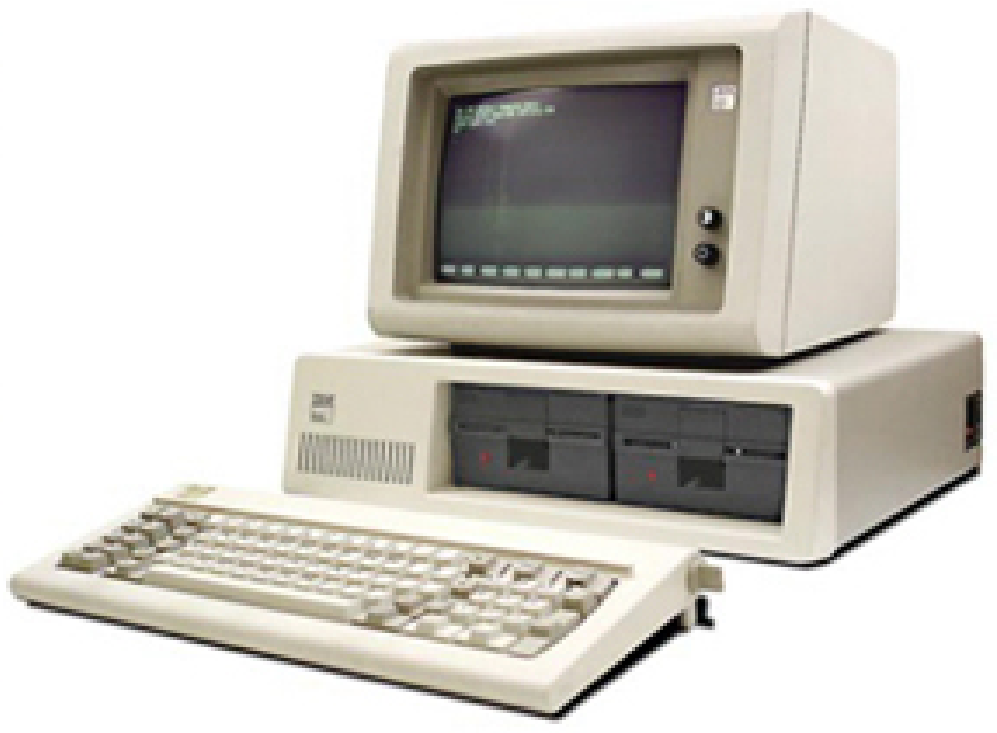

Vol. 3.1 (2015)

ISSN 2182-8830

'Artes, Média e Cultura Digital'

Paulo Silva Pereira e Pedro Serra (orgs.) 


\title{
Tacto/Contacto: Processos de Experienciação Háptica no Corpo Cíbrido Diogo MARQUES
}

\author{
CLP | Universidade de Coimbra
}

Bolseiro da FCT

\begin{abstract}
Resumo
Com o presente artigo proponho-me reavaliar a utilização do adjectivo "háptico" na sua relação com a intensificação da procura de tangibilidade entre ser humano e máquina, nomeadamente através de experiências multissensoriais possibilitadas por processos de realidade/virtualidade misturada. Partindo de uma tradição haptológica de linhas filosóficas, que tem oscilado entre "ocularcêntrica" e "tactilocêntrica", o artigo explora ainda as noções de toque, de gesto e de contacto, nas suas mais variadas acepções, utilizando-se esta última para explorar a ideia de corpo cíbrido em processos de experienciação háptica com base na Interface Humano-Máquina (IHM). Palavras-chave: háptico; toque, gesto, contacto; corpo cíbrido; interface humanomáquina.
\end{abstract}

\section{Abstract}

With this paper it is my intention to reevaluate the use of the adjective "haptic" with respect to a growing demand for tangibility between human and machine, namely through multisensorial experiences made available by mixed reality/virtuality. From a haptological philosophic perspective, a tradition oscillating between the emphasis on vision and the emphasis on touch, this paper also intends to analyze notions of touch, gesture and contact, in their multiple meanings, in which the latter serves as a probe to explore the idea of cybrid bodies within processes of haptic perception in HumanMachine Interface (HMI). Keywords: haptic; touch, gesture, contact; cybrid body; human-machine interface.

How is one to believe that touch cannot be virtualized? Jacques Derrida

"Quando os nossos olhos (se) tocam"

$\mathbf{E}$

m The English Patient (1992), romance de Michael Ondaatje, o leitor depara-se em certo momento com a seguinte série de instruções para ler Kipling:

Read him slowly, dear girl, you must read Kipling slowly. Watch carefully where the commas fall so you can discover the natural pauses. He is a writer who used pen and ink. He looked up from the page a lot, I believe, stared through his window and listened to birds, as most writers 
who are alone do. Some do not know the names of birds, though he did. Your eye is too quick and North American. Think about the speed of his pen. What an appalling, barnacled old first paragraph it is otherwise. (94)

O fragmento invocado, suficientemente ilustrativo dos artifícios literários levados a cabo pelo escritor canadiano, revela-se crucial para a problemática que se pretende explorar com este artigo. Desde logo, pelas "materialidades da escrita" que nele são invocadas: do gesto da mão "protética" de Kipling (mediado por outra "subprótese"1 representada pelo seu kit de escrita), que estabelece um "contacto" entre corpo ${ }^{2}$ e a tecnologia do papel, ${ }^{3}$ às pausas naturais para observação do quadro exposto pela sua janela, criando-se, pela sua conjugação, uma perfeita triangulação entre corpo biológico, mundo e texto. Mas a referida passagem é ainda reveladora de uma outra subcamada de "materialidades", neste caso, da leitura, e sedimentada em diferentes instâncias de leitor. Uma primeira, trazida pela personagem de Anne, cuja chamada de atenção, por parte do seu interlocutor, para o seu olhar demasiado norte-americano, por si só, deixa quase tudo dito. E uma segunda, incorporada nos leitores de Ondaatje, que, pela mediação deste, se tornam também leitores de Kipling. Porém, nesta última, o artifício literário torna-se de tal modo autorreflexivo (e autorreferencial) que até o leitor mais atento sentirá a necessidade de retroceder uma série de linhas para reler o excerto evocado.

\footnotetext{
${ }^{1} \mathrm{O}$ potencial e eficácia da metáfora protética, em utilizações que extravasam o campo clínico, parecem ter uma tal abrangência ao ponto de permitirem o estabelecimento de uma subdivisão em subpróteses e suprapróteses, isto é, se concordarmos com a variante pós-humanista que vê o corpo biológico enquanto "prótese original que todos aprendemos a manipular" (Hayles: 1999: 3), de tal modo que, na extensão ou substituição do corpo por próteses (subpróteses?) vislumbra-se a continuação de um processo anterior ao nascimento. Por exemplo, no acto de escrever, não só a mão, os dedos e os utensílios de escrita permitem estabelecer uma sequência protética, como se torna possível ampliar esta mesma sequência ao próprio acto de inscrição numa dada superfície, apresentando-se a inscrição permanente enquanto "memória protética”. Cf. Ryan, 2006: 22.

${ }^{2}$ A noção de corpo é aqui utilizada, como em outros momentos deste artigo, com base na acepção que tem vindo a ser-lhe atribuída por vários investigadores, que, contrariando um certo dualismo cartesiano, o estendem para lá da sua recorrente conotação com o corpo biológico. Para a sua contextualização torna-se importante a introdução de noções como "cognição distribuída" e "intermediações". Ver Hayles, 2010.

${ }^{3}$ São vários os autores que fazem referência à ideia de que a sua escrita é mediada pela ideia figurada de "mão com vida própria". Por exemplo, António Lobo Antunes, quando afirma: "Nos momentos felizes, a mão anda sozinha. A cabeça está a ver ao longe e fica contente, porque são as palavras certas que a cabeça não encontraria. É a mão. (...) É a mão que escreve. A nossa mão é mais inteligente do que nós. Quando estou a escrever, parece que estão a ditar-me e a mão a reproduzir." Excertos de entrevista com António Lobo Antunes, conduzida por Maria Augusta Silva (2004). "Saber ler é tão difícil como saber escrever". Diário de Notícias (s/e, novembro 2004). 8 Fev 2015. http:/ /www.dn.pt/inicio/interior.aspx?content_id=588769\&page =-1
} 
Desta feita, com as devidas pausas emuladoras da velocidade de escrita do autor original. $^{4}$

Talvez por esta razão Milena Marinkova nos apresente a escrita de Ondaatje enquanto potenciadora de uma estética capaz de forjar uma relação corpórea íntima entre público, autor e texto (2011: 4). Estética que classifica como háptica, justificando a apropriação do adjectivo ${ }^{5}$ com base numa ressignificação da palavra levada a cabo por diversos investigadores, nomeadamente em áreas como os estudos fílmicos e artísticos, e que, partindo de teorias do afecto, ${ }^{6}$ privilegiam o "toque" e a "textura" da imagem em detrimento de uma visualidade puramente "óptica". Por exemplo, Laura Marks, sobretudo com referência à imagem cinematográfica, defendendo a hipótese de uma visualidade háptica na forma como "experienciamos o tacto quer na superfície quer no interior dos nossos corpos” (2002: 2; tradução nossa), ou Patrícia Silveirinha (2013), servindo-se de um quadro teórico composto por Heidegger, Jünger, Benjamin e McLuhan para reflectir sobre a "função háptica das novas imagens tecnológicas". Deste modo, por meio da metáfora sinestésica do "olho que toca", justifica-se a possibilidade de este órgão poder preencher uma "função não-óptica". Uma "percepção háptica" que Deleuze

\footnotetext{
${ }^{4}$ Não esquecendo uma outra sequência de "materialidades multissensoriais" subjacentes, como sejam o humedecer do dedo para virar a página, o cheiro e a textura do papel, ou outras, mais ergonómicas, como o acto de segurar o livro a uma distância precisa do olhar.

${ }^{5}$ A palavra, do grego bapthesthai, é frequentemente utilizada com referência à modalidade sensorial exteroceptiva de tacto e às sensações tácteis, ainda que, tal como demonstrado por Jacques Derrida, a sua utilização por Aristóteles esteja longe de ser clara, constituindo-se enquanto aporia (Derrida, 2005: 5). Ainda, e de acordo com Mark Paterson, a sua actual ambiguidade parece derivar das múltiplas apropriações pelas mais variadas áreas do conhecimento, como sejam a psicologia da percepção e as engenharias (2007: 4). Porém, no contexto deste ensaio, preferimos seguir com Brian Massumi, na sua clara separação entre sensibilidade táctil, propriocepção e interocepção, três instâncias distintas do que é usualmente interpretado como háptico: "[...] [P]roprioception, defined as the sensibility proper to the muscles and ligaments as opposed to tactile sensibility (which is "exteroceptive") and visceral sensibility (which is "interoceptive"). Tactility is the sensibility of the skin as surface of contact between the perceiving subject and the perceived object. Proprioception folds tactility into the body, enveloping the skin's contact with the external world in a dimension of medium depth: between epidermis and viscera". Ver Massumi, 2002: 58.

${ }^{6}$ Nas notas e agradecimentos que introduzem a versão inglesa de $A$ Thousand Plateaus ([1980] 1987), segundo volume de Capitalism and Schizophrenia, da autoria de Gilles Deleuze e Félix Guattari, o seu tradutor, Brian Massumi, introduz um pequeno glossário no qual procura avançar uma definição de afecto, e que importa aqui recuperar: "AFFECT/AFFECTION. Neither word denotes a personal feeling (sentiment in Deleuze and Guattari). L 'affect (Spinoza's affectus) is an ability to affect and be affected. It is a prepersonal intensity corresponding to the passage from one experiential state of the body to another and implying an augmentation or diminution in that body's capacity to act. L'affection (Spinoza's affectio) is each such state considered as an encounter between the affected body and a second, affecting, body (with body taken in its broadest possible sense to include "mental" or ideal bodies)." "Notes on the Translation and Acknowledgements". Ver Deleuze \& Guattari, 1987: xvi.
} 
e Guattari contrapõem, na adaptação de teorias da percepção como as de Alois Riegl, Henri Maldiney e Henri Bergson (Derrida, [2000] 2005: 123-124), a uma outra tipologia de percepção, neste caso, "óptica" (Silveirinha, 2013: 26). Por outras palavras, uma "óptica tendencialmente táctil" resultante de "efeitos especificamente cinematográficos que embalam o corpo do espectador numa relação directamente física, e não estritamente [...] racional ou emocional" (ibid.), e que Walter Benjamin ilustra com a imagem de "golpes que o espectador vai recebendo" ([1936] 2006: 237).

A problemática de uma relação dita "física", embora possa ser validada com ressignificações de toque e de gesto, acaba, no entanto, por nunca ultrapassar a barreira metafórica que a assombra. ${ }^{7}$ Barreira que parece ser levada ao extremo na marca de assinatura do cineasta Robert Bresson, caracterizada pelos grandes planos de mãos de todos os tipos e feitios, desde a mão que acaricia e redime à mão que destrói e conspurca. ${ }^{8}$ Afectos que nós, espectadores, vemos e, por isso, gestos feitos e desfeitos que afectam e que (nos) afectam, ainda que sempre mediados pela visão.

Importa, no entanto, esclarecer que uma tal problemática pode ser igualmente encontrada em outros modos de expressão artística, por exemplo, na pintura de Caravaggio, sendo que a tridimensionalidade orgânica dos jogos de luzes e sombras (chiaroscuro) bastaria para justificar a sua convocação. ${ }^{9}$ Assim, da mesma forma que Bresson o fez com a técnica do cut-up, o que o universo de representação caravaggiano parece evidenciar são potências e actualidades de toques e de gestos que se fazem anunciar tanto pelas mãos como pelo olhar. E, até certo ponto, é o que nos demonstra Kirmen Uribe, numa passagem retirada do prefácio a uma série de poemas seus reunidos sob o curioso título de Mientras Tanto Cógeme la Mano:

Para Caravaggio los gestos eran lo más importante. Un dia vio cómo recogían del río el cuerpo de una prostituta ahogada. No podía quitarse de la cabeza la expresión de la muerta. Y utilizó esa misma expresión para representar a la virgen en La Virgen Muerta. Era la primera vez que un ar-

\footnotetext{
${ }^{7}$ Partindo-se de Derrida, esta utilização de metáforas, e metonímias, para descrever eventuais cruzamentos entre as modalidades sensoriais de visão e tacto (frequentemente por meio das sinédoques do olho e da mão) é algo que não encontra consenso numa reconhecida tradição haptológica na filosofia, contribuindo, também elas, para a continuidade do estatuto de aporia que Aristóteles atribuía ao tacto. Neste sentido, se pensadores como Henri Bergson promovem a utilização de metáforas, no sentido de abalar as fronteiras demasiado rígidas dos conceitos, outros, como Husserl, preferem uma via fenomenológica que não abre espaço para tais abstracções. Ver Derrida, 2005: 122; 169.

${ }^{8}$ Veja-se, a este respeito, um interessante ensaio visual encomendado pela companhia norte-americana de video-distribuição The Criterion Collection, e no qual se fazem representar, ao longo de pouco mais de quatro minutos, uma vasta panóplia de grandes planos de mãos retirados da filmografia de Robert Bresson. Ver kogonada, 2014. http://www.criterion.com/current/posts/3196-hands-of-bresson

${ }^{9}$ Ver Silveirinha, 2013: 369-372.
} 
tista pintaba esa escena como nocturna. (...). En sus cuadros, apunta Berger, los personajes están siempre a punto de tocarse. Una pluma acaricia el muslo de un muchacho. Si no pones atención ni siquiera te das cuenta. La mano de la virgen está por debajo del manto del niño, acariciándole lentamente. Un ángel tira de la mano de San Pedro como una prostituta tiraría de la mano de cualquier cliente. Son muchos los gestos, y la mayoría denotan el deseo erótico (2008: 7-8).

Embora a descrição de Uribe incida quase sempre no gesto enquanto próprio do universo específico da mão, que melhor exemplo para justificar a razão de ser de uma determinada tangibilidade intangível que permeia toda a dimensão aurática da arte ocidental? Três palavras elevadas ao cubo pela mão de Jean-Luc Nancy: "mè mou haptou"; "noli me tangere"; "DO NOT TOUCH". Como querendo dizer que única e exclusivamente pela potência de um contacto, que não se quer constituir como pura visão nem poderá nunca constituir-se como puro tacto, se torna possível tocar ou atravessar a superfície (Nancy 2008 e 2000).

Talvez por isso, não estando em causa a validade destes toques e gestos quando aplicados aos objectos de estudo supramencionados, e apesar da tentativa de restituição da tactilidade pela sua redução metafórica, tais esforços acabem inevitavelmente por reiterar uma sobreposição constante da visão sobre o tacto, de um sentido sobre outro. Razão pela qual esta hipótese háptica acaba por revelar-se "curta", sobretudo quando se trata de, como refere Maria Engberg em relação a obras literárias digitais desenvolvidas como aplicações para dispositivos multitoque, desvelar o "valor do toque [e do gesto] enquanto movimento performativo e como principal portal sensorial para uma experiência estética" (2013: 20). Ou como afirma Erkki Huhtamo, com referência a arte interactiva:

Although useful, the notion of "haptic visuality" cannot be applied as such to the analysis of phenomena like interactive art, where the body sometimes coupled with the 'bodyimage', as in the case of the 'levitating' virtual hands in VR applications - is directly involved. The haptic gaze is supported - and perhaps contradicted? - by other corporeal operations. Quite clearly, any segragation of the senses from each other is out of question. As McLuhan stated, "tactility is the interplay of the senses, rather than the isolated contact of skin and object". This applies well to interactive art that often engages not only sight and touch, but sound as well’'. (2007: 73-74)

Torna-se necessário, portanto, espreitar para o outro lado da superfície e perceber que outros toques e gestos nos aguardam - mas não atravessando 
completamente, ficando por ora no limiar, para fazer uso, uma vez mais, das palavras de Nancy. ${ }^{10}$

\section{"As mãos (...) pálpebras imensas"}

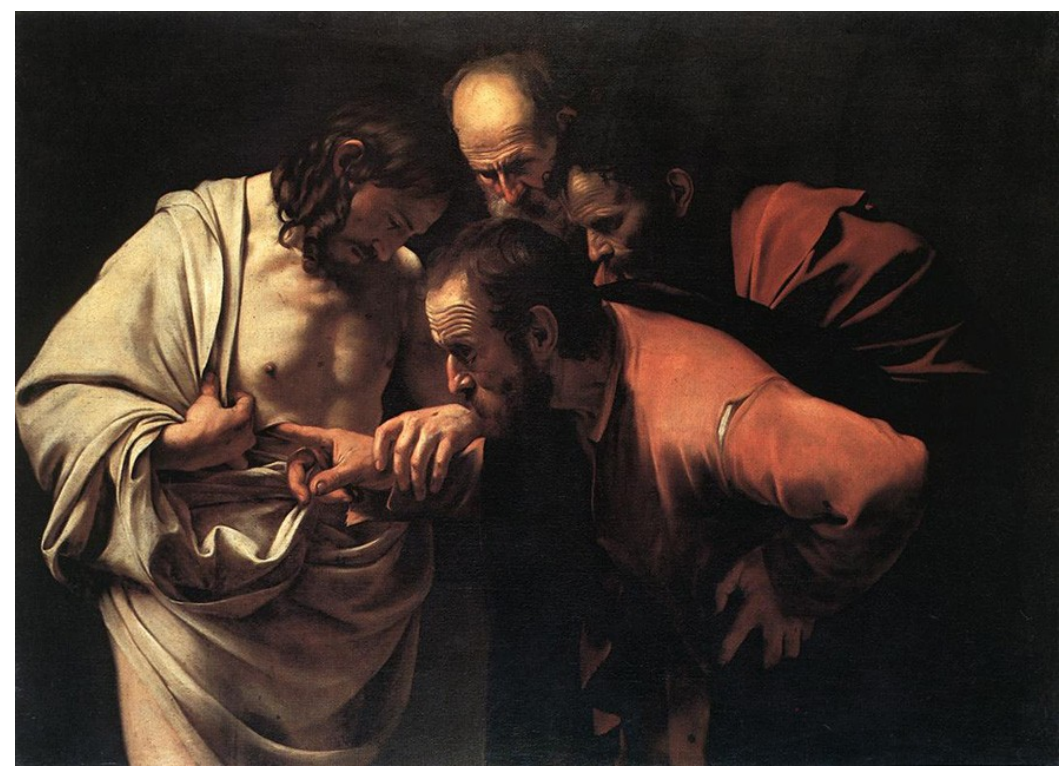

Figura 1. Caravaggio, Incredulità di San Tommaso (c. 1601) (C) Sanssouci Palace, Potsdam.

O contraponto pode ser iniciado, precisamente, por meio de uma outra representação caravaggiana, mais concretamente, pela Incredulità di San Tommaso (c. 1601), na qual o apóstolo, na iminência de uma confirmação da presença actual de Cristo, é convidado e guiado pela mão deste a penetrar as suas feridas e fronteiras carnais [Figura 1]. Uma confirmação por meio de um outro tipo de toque (e de gesto), passível de ser ilustrado com o que Diderot, na sua Carta sobre a Cegueira, descreve do seguinte modo: "[D]e todos os sentidos, o olho é o mais superficial, (...) o tacto o mais profundo e filosófico" (1749, apud Paterson, 2007: 1; tradução nossa). Dito de outra forma, um

${ }^{10}$ Vale a pena recuperar as palavras iniciais do ensaio de Jean-Luc Nancy intitulado "On The Threshold" (na sua tradução inglesa), escrito por ocasião de uma conferência no Louvre e no qual Nancy esboça considerações pertinentes sobre o tacto e o debate em torno da "primazia do tacto" a partir de uma análise sui generis de "A Morte da Virgem", de Caravaggio: "So, we have entered there where we will never enter, into this scene painted on a canvas. [...] We can't exactly say that we have penetrated there, but neither can we say that we are outside. We are there in a manner older and simpler than by any movement, displacement, or penetration. We are there without leaving the threshold, on the threshold, neither inside nor outside-and perhaps we are, ourselves, the threshold, just as our eye conforms to the plane of the canvas and weaves itself into its fabric". (Nancy, 1996: 57) 
entendimento de tacto que representa um movimento inverso, agora pela sua sobreposição à visão, e que, à primeira vista, parece contrariar a ideia recorrente de uma determinada cultura visual própria de uma "sociedade ocularcêntrica" (Jay, 1993: 3).

Trata-se, portanto, de uma inversão de hierarquias, que importa explorar. Isto é, à referida tendência para a sobreposição da visualidade que a redução metafórica permitida pelas teorias do afecto não elimina, antes amplifica, parece contrapor-se agora uma determinada "fetichização" do conhecimento directo pelo tacto que, de acordo com Derrida, é resultante de um "haptocentrismo" pós-cartesiano, cujos focos de incidência vão repercutindo-se ao longo de uma vasta tradição haptológica de linhas filosóficas. Por exemplo, na fenomenologia de Husserl, na qual a "primazia" do tacto é entendida pelo filósofo francês enquanto continuidade de um "humanualismo" "11 cujo hipocentro já havia localizado em Maine de Biran. Por outras palavras, a identificação de uma sobreposição do tacto em relação aos outros sentidos (sobretudo a visão), que atinge o seu auge no estabelecimento de "uma experiência táctil preeminente no acto do toque manual ou digital" (Pirovolakis, 2013: 106; tradução nossa). O que significa ora a inevitabilidade de uma outra metáfora sinedóquica e sinestésica, agora sob a forma de uma "mão que vê", senciente e sensível, ora o estabelecimento de um novo paradoxo, que Derrida descreve da seguinte forma: "[...] more than any other part of the body proper, the hand has imposed a detour leading through visibility and exposition to a surface, precisely when it was meant better to illustrate the pure, psychic auto-affection of the touching-touched." (2005: 181)

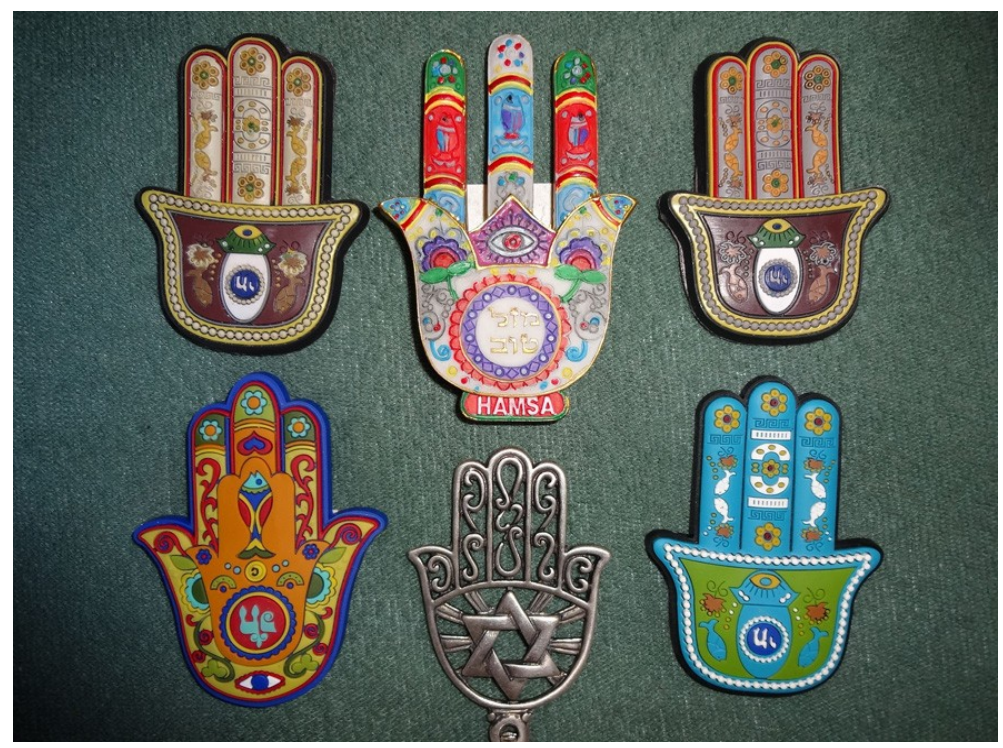

Figura 2. Colecção privada de hamsa. (C) Bluewind.

\footnotetext{
${ }^{11}$ Ver Derrida 2005: 152-153.
} 
Mas uma tal ideia de mão, aspirando a uma omnisciência e omnipresença intangíveis, não se esgota no referido haptocentrismo, sendo igualmente resultante de um processo de mistificação presente num imaginário colectivo, ancestral e transcultural [Figura 2]. ${ }^{12}$ Tomemos como exemplo a comédia $M y$ stepmother is an alien (1988), ${ }^{13}$ na qual Kim Basinger interpreta o papel de um ser alienígena que vem à Terra com o objectivo de obter acesso aos detalhes de um projecto científico que pode salvar o seu planeta de origem. Passando o plot típico da comédia romântica hollywoodesca, interessa-nos, porém, destacar uma pequena sequência de imagens que a película reproduz. Sequência que começa no acesso subreptício da personagem principal aos dados guardados num terminal de computador, numa espécie de leitura táctil “à la minute", isto é, no contacto da palma da mão e dos dedos com o ecrã, evitando assim a eventual demora que uma leitura "puramente" visual implicaria. Mas experiência que sai, no entanto, gorada, encerrada pela irónica frase “that's kid's stuff” e pelo rasto de mão que vai desaparecendo a pouco e pouco no ecrã. ${ }^{14}$ Não obstante, a referida sequência vai mais além na representação de um determinado desejo em aceder de modo imediato ao conhecimento pelas capacidades "hápticas" da prótese cutânea: ou seja, não satisfeita com os resultados obtidos no contacto com o meio digital, a personagem de Basinger vira-se então para uma outra tecnologia, o códice, acedendo, por exemplo, a The Complete Works of William Shakespeare pela simples colocação do antebraço entre fólios. Ora, se no contacto com o ecrã fantasmático, a personagem de Basinger não consegue evitar a co-utilização da visão na leitura dos dados, na cena em questão o olho é agora completamente dispensado de contacto directo com o suporte, ficando apenas o gesto vago de um olhar fixo (gaze) e distante que, embora sempre influenciado pela percepção táctil, não evita, ainda assim, a passagem de alguma linguagem emotiva. ${ }^{15}$

Deste modo, o que estas duas cenas parecem pressupor é uma natural utilização de diferentes próteses cutâneas, dependendo da ergonomia imposta por cada um dos suportes, mas enfatizando uma interligação entre dois caminhos evolutivos: o da tecnologia e o do próprio ser humano enquanto ser biológico. Porém, como explicar que uma tal co-evolução - à medida que o ser humano foi substituindo gradualmente as suas capacidades motoras e reflexivas pela produção de novas tecnologias, potenciando-as num sentido que anula, em larga medida, a natural imperfeição do corpo biológico - tenha ido ao encontro de uma nova prótese, no sentido contrário ao do antebra-

\footnotetext{
${ }^{12}$ Por exemplo, a hamsa, ou "Mão de Fátima", símbolo representado por um olho aberto na palma de uma mão, e que é frequentemente utilizado em muitas culturas como talismã (Cf. Dur, 2015: 22).

${ }^{13}$ Benjamin, Richard (1988). My stepmother is an alien. Produção: Weintraub Entertainment Group. Distribuição: Columbia Pictures. 105 minutos. 19 Jan. 2015. https://www.youtube.com/watch?v=XYpEC_A4IbM

${ }^{14}$ Idem, min. 44:00-44:25.

${ }^{15}$ Idem. min. 44:25-45:26.
} 
ço ${ }^{16}$ Leroi-Gourhan avança duas possíveis explicações: primeiro, tendo em conta as descobertas de Broca de áreas adjuntas no cérebro responsáveis pelas capacidades locomotora e reflexiva (pelo gesto e pelo discurso); segundo, pelas consequências a nível reflexivo despoletadas pela passagem de uma postura quadrúpede a uma postura bípede/erecta (1993: 240-242), libertando, igualmente de modo gradual, (1) o antebraço da sua função locomotora; (2) antebraço e mão das suas funções de ferramenta, que passam a servir de força motriz; (3) praticamente todo o corpo biológico das suas funções reflexivas e motoras, num work in progress rumo à sua (quasi) obsolescência.

\section{"os dedos/complicada regra de cinco simples"}

Fica, no entanto, o dedo, o dígito, essa figura que, embora ainda se faça representar com resquícios de uma certa autoridade e paternalismo que a mão já pressupõe (dedos e mãos que indicam, que apontam, que acusam), parece carregar em si grande parte do peso das mediações actuais entre ser humano e máquina. É o que parece dizer-nos Fernando Aguiar, com a sua obra experimental O DEDO (1981). Uma brochura, em forma de dedo (uma outra acepção de "formato digital"), na qual o dedo se faz representar em 22 andamentos. Nesta, o leitor depara-se, logo no início, com um primeiro aviso (um primeiro dedo), no interior do qual pode ler-se: "IMPORTANTE:/manter o dedo/bem alto e vivo/durante a leitura" [Figura 3]. E à medida que o leitor vai percorrendo estes dedos outros, com os seus próprios dedos, ${ }^{17}$ uma série de poemas que variam entre os formatos discursivo e visual, por meio dos quais o dedo vai revelando a cada passo a sua condição metonímica. Por exemplo, o $14 .^{\circ}$ andamento, apresentando uma série de acções verbais, que por sua vez surgem associadas a uma outra série de adjectivos que vão classificando os múltiplos e distintos dedos: “[...] o dedo doente delira/o dedo demente demite/o dedo desfeito respira/o dedo deprimido permite [...]"[Figura 4]. Um exercício que parece alcançar um duplo estatuto metonímico no verso "o dedo digital lancha", e que Vieira sintetiza do seguinte modo: "O dedo que representa o homem significa também o dígito

\footnotetext{
16 Pense-se, por exemplo, nas técnicas ancestrais de medição pelo cúbito e, posteriormente, pelo dígito.

${ }^{17}$ A obra pode ser consultada na íntegra a partir da página Web do Arquivo Digital da PO.EX, em: http://po-ex.net/taxonomia/materialidades/planograficas/fernandoaguiar-o-dedo. Constate-se o facto de, pese embora o seu formato digital, o dedo do leitor continuar, nesta leitura, a ter um papel fundamental, já não no contacto directo com a página, mas com o "dígito" por meio das interfaces que o medeiam (ecrã e rato). Importa ainda distinguir esta obra, em suporte de papel, de uma outra obra posterior criada pelo mesmo autor, mas enquanto "re-mediação digital" criada em Flash $^{\mathrm{TM}}$. Falamos de Soneto Digital, cuja interface parte de um dos poemas de $O$ DEDO, mais concretamente o $200^{\circ}$ andamento, também intitulado "soneto digital". Ver Vieira 2012: 73-110.
} 
que representa a linguagem da máquina. Ou seja, a tecnologia torna-se natural e a máquina humaniza-se". (2012: 106)

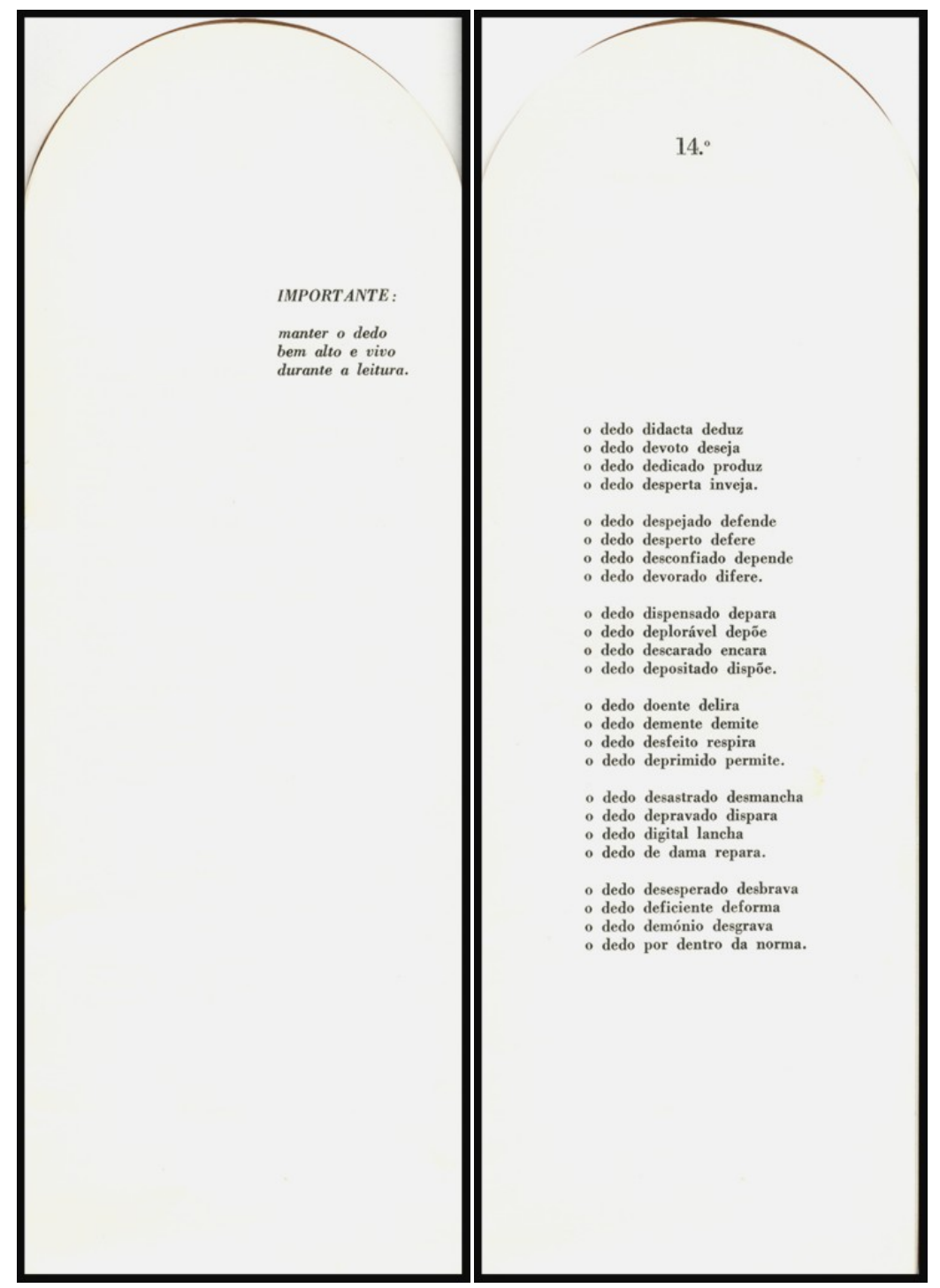

Figuras 3 e 4. Fernando Aguiar, O DEDO (1977): página 5 e página 21. Cortesia de Fernando Aguiar.

Não querendo aprofundar demasiado a relação etimológica entre "dedo" e "digital" - do latim digitus - que humanos e computadores partilham e que, no contexto dos media digitais, diversos investigadores têm vindo a desmis- 
tificar, ${ }^{18}$ será contudo pertinente recuperar duas destas visões. Por exemplo, Anne Mangen, que evidencia a tactilidade e corporeidade presentes na origem latina do termo "digital" (2006: 37), ou Marianne van den Boomen, ao apontar para o "digital" enquanto prolongamento do dedo humano:

It is an extension of the ability to point at, touch, tap and push on things, as well as the ability to count discrete entities, to assign numbers to things and to remember them. All in all, this constitutes the basic ability to represent things by embodied symbols, and to do things with symbols and with machines. In other words, human acts - acts of manipulation as well as acts of attribution and interpretation, performed by designers and users - are indispensable for the operation of a computer, no matter how sophisticated its machinery. This is no trivial statement [...], it has profound epistemological and political implications if we acknowledge the human attribution labor that is incorporated in digital praxis, along with the digital-material configurations that enable and disable particular practices. $(2014,32)$

Como se o quase-toque que a Creazione di Adamo (c. 1511) de Michelangelo Buonarroti representa, de repente, se transfigurasse por completo, e se tornasse realmente sináptico, agora sob a forma de dois dedos que se tocam, e não apenas um dedo autoritário que quase-toca uma mão quase-passiva. Mas tão exigente exercício acarreta o mesmo problema de haptocentrismo explorado na secção anterior, neste caso, pelo dígito enquanto metonímia e, simultaneamente, pela recorrente associação (talvez demasiado recorrente), com a noção de prótese. Para que o exercício funcione será necessário alterar, de igual modo, a perspectiva dos corpos, mexendo em todo o quadro (com o eventual risco de se vir a destapar um dos lados para cobrir o antípoda).

\section{"O teu corpo é o meu corpo/ o meu corpo é o teu corpo"}

Falamos agora de corpos que se tocam numa mesma horizontalidade, isto é, eliminando qualquer vestígio de uma perspectiva hierárquica, parental, ou diagonal. Uma horizontalidade reminiscente das palavras de Marshall McLuhan, ao alertar para os perigos de "tratar os novos media como humildes servos" (2003: 4; tradução nossa), ou de Donna Haraway, uns anos mais tarde, ao afirmar: "The machine is not an it to be animated, worshipped, and dominated. The machine is us, our processes, an aspect of our embodiment"

${ }^{18}$ Florian Cramer, numa análise do termo "pós-digital", afirma que "algo pode perfeitamente ser 'digital' sem ser electrónico, e sem que envolva zeros e uns binários" (por exemplo, o alfabeto romano, as teclas de um piano, os tipos móveis da imprensa de Gutenberg, enquanto sistemas digitais). Assim como é possível desmistificar a ideia de que o computador é sinónimo de electrónico. Cf. Cramer, 2014. 
(1991: secção “Cyborgs: a myth of political identity”, ๆ17). Visões precursoras de um estado simbiótico entre ser humano e máquina, que encontram repercussão quer nos feedback loops descritos por N. Katherine Hayles enquanto intermediações resultantes de um processo de "cognição distribuída" (2010: 48-51) quer na noção de "cibercomunicação cíbrida" explorada por Domingues e Venturelli:

O híbrido soma propriedades do ciber e torna-se cíbrido. O potencial do digital, levado ao paroxismo, incrusta virtual com virtual no espaço físico, homologando desejos ficcionais de viver em mundos paralelos. Objetos, cenas, visualização sintética, geografias misturadas são espaços e lugares cíbridos para a existência. A Realidade Aumentada e suas versões tira o foco do virtual como evasão do real e, dialeticamente, acentua a potencialidade do virtual ampliando a realidade (2007: 109).

Sendo que, de ambas as propostas parece sobressair a hipótese de uma outra acepção de toque e de gesto, tão actual quanto virtual, vislumbrando-se um novo entendimento de háptico que extravasa as suas habituais instrumentalizações. ${ }^{19}$ Portanto, outros toques e outros gestos, que Derrida começa por desvelar, praticamente no final de On Touching - Jean-Luc Nancy:

A description is needed of the surfaces, the volumes, and the limits of this new magic writing pad, which exscription touches in another way, with another kind of "exactitude" or "punctuality," precisely, from the keyboard to the memory of a disk said to be "hard." [...] It is a pretext to bring up another challenge, a supplementary one, of the technical supplement challenging the discreet, discrete, and calculable multiplicity of the senses - and the assurance that touch is on the side of the act or the actual, whereas the virtual partakes more of the visual, with the appearing of phainesthai, that is, with the phantasm, the spectral, and the revenant. One spontaneously has the tendency to believe that touching resists virtualization. [...] How is one to believe that touch cannot be virtualized? (2005: 41)

${ }^{19}$ A ciência designada como háptica (baptics), que tem vindo a ser desenvolvida nos últimos anos, frequentemente com base em parcerias que envolvem laboratórios universitários e a indústria tecnológica digital, destaca-se sobretudo pelas suas potencialidades e aplicações nas mais variadas áreas do conhecimento. Exemplo disso mesmo é o Haptics Group, inserido no GRASP Lab da Universidade de Pennsylvania, com projectos inovadores como o caso de "Haptography", no qual se investiga e aplica a possibilidade de virtualização da tactilidade (cutânea e proprioceptiva). Porém, embora o espaço reservado para este ensaio não permita uma análise extensa das particularidades em torno desta ciência emergente, será porém útil situá-las no contexto desta argumentação, no sentido em que, em larga medida, as suas bases fundacionais comprovam a teoria do haptocentrismo exposta sobretudo por Derrida, resultando numa série de instrumentalizações do termo que parecem contornar uma longa tradição filosófica dedicada ao estudo da percepção. 
Gestos digitais a que Carrie Noland faz referência numa contraargumentação da ideia recorrente de que as interfaces digitais são meras próteses culturais que atenuam progressivamente o laço biológico que o "gesto" de escrever à mão mantém com o texto. Com base numa série de obras literárias digitais que centram as suas poéticas numa intensa exploração metamedial da multissensorialidade e da multimodalidade digital, Noland denuncia vestígios de uma protoescrita contaminada pelas práticas artísticas avant-garde, que amplifica os impulsos cinéticos do corpo no ecrã. (2006: 217-243) E na mesma linha de pensamento, Maria Angel e Anna Gibbs, reforçando a ligação ancestral entre gesto e palavra, mas, desta feita, colocando a ênfase no movimento e nos gestos do corpo nos actos de escrita e leitura. Processos que os "novos" media tecnológicos permitem recuperar e actos que, pelo seu dinamismo e animismo, se encontram intimamente ligados com a produção de significado:

What we do with our bodies when we read and write with new media and new media interfaces is becoming qualitatively different to our quiet and relatively still engagement in the scenes and scenarios of bookish writing and reading. Gesture is elicited from us when we play with or operate technologies and read texts, and writers seem to be actively programming texts that express behaviors such as movement and sound, [...] these changes, apparently minor in their everydayness, are more significant than might first appear. (2013: ๆ 3-4)

Contudo, talvez "contacto" possa ser, no contexto de uma "intermultissensorialidade" convocada pela multimodalidade digital, melhor palavra do que um "simples" gesto ou toque. Já não no sentido de um contacto que prende e que controla (to grasp) ou que permite alcançar (to attain), com o gesto de uma mão ou o toque de um dedo, mas sim enquanto interconexão e intercomunicação entre corpos cíbridos. Com toda a panóplia de diferentes utilizações, por exemplo, em campos como a aeronáutica ${ }^{20}$ ou a electrotecnia $^{21}$, entre tantos outros, "contacto", no limite, pressupõe uma ligação entre duas tangentes, ou dois pontos de contacto. Mas uma tal ligação pode ser entendida como mutual, ou cíclica, exigindo, assim, modos renovados de pensar a nossa relação com os media.

\footnotetext{
${ }^{20}$ No contexto aeronáutico, a palavra "contacto" prende-se com uma velha expressão do tempo dos primeiros aeroplanos (ainda hoje utilizada na necessidade de propulsionar uma hélice de modo manual), cujo funcionamento estava dependente de uma segunda pessoa incumbida de mover a hélice no momento do arranque do motor. Embora não seja o termo adequado, a sua utilização é ainda hoje a mais recorrente, pela constante confusão que as expressões "switch on" e "switch off" causavam (as expressões correctas para indicação de que o motor se encontraria ligado ou desligado).

${ }^{21}$ Por exemplo, a junção de dois condutores eléctricos pela qual passa a corrente.
} 


\section{"Birds Singing Other Birds' Songs"}

Como falar de ciclos - falaremos também de (e)migrações - sem fazer referência a um dos seus símbolos mais marcantes? Precisamente, a mais intocável e etérea das aves, ave mágica, cuja vida, segundo a lenda, se estende por quinhentos anos, para depois arder até à morte e voltar a renascer das cinzas. Num processo, também ele, diríamos, de retroalimentação (feedback loops), isto é, do palíndromo - $\mathrm{OVO}^{22}$ - que dá a vida ao húmus de cinza a que fica reduzido o corpo. A fénix. Ave escolhida por Silvestre Pestana para o título de uma série de performances apresentadas entre 2009 e 2010, com diversas “encarnações" e "descorporificações". Um primeiro momento: FÉNIX ação: socialmente reprovado por envelhecimento prematuro (2009), levado a cabo por Pestana na galeria portuense Uma Certa Falta de Coerência e, em simultâneo, pelo seu avatar Vitos Flores, na plataforma de realidade virtual Second Life ${ }^{\text {TM }}$ (SL) [Figuras 5 e 6]. ${ }^{23}$ Podendo ler-se o seguinte manifesto no press release que antecedeu o evento:

$[U]$ ma reflexão artística sobre a construção social dos comportamentos narcísicos, ditados pela mitologia das vivências funcionais. Neste encontro, fazem-se cruzar virtualmente o avatar e o seu criador, num duplo espaço fechado (estufa) que deste modo reforçam o valor 3D potencializado, onde o desejo é a terra prometida da regeneração. FÉNIX é assim a missão impossível de ser outro com este meu invólucro que não seja uma auto renderização. ${ }^{24}$

\footnotetext{
${ }^{22}$ A utilização do palíndromo "OVO" em poemas visuais figurativos é bastante fecunda, remontando a Símias de Rodes. É Pedro Reis que o relembra, reproduzindo as palavras de Décio Pignatari no artigo "Ovo novo no velho" (1960): "Símias de Rodes, lá por 300 a.C., escreveu um ovo estupendo. Technopaegnia. Está na Antologia Grega e na pequena antologia de poemas em forma de coisa organizada pelo jovem poeta norte-americano Charles Boultenhouse para Art News Annual XXVIII, 1959” (Décio Pignatari [1987], apud Reis, 1998: 42).

Por sua vez, também Ana Hatherly nos fala deste "ovo" fundacional, apresentando-o da seguinte forma: "Trata-se de um poema bucólico composto graficamente em forma de ovo, sendo essa forma usada como metáfora do processo poético. A sua leitura exige regras especiais: deve começar-se pela primeira linha superior, saltando depois para a última linha inferior, seguidamente retomando a segunda linha superior para descer à segunda inferior e assim sucessivamente até se atingir o centro." (1975: 7).

${ }^{23}$ Uma outra evidência da metáfora cinestésica da mão que vê, no logótipo que serve como imagem de marca da plataforma Second Life ${ }^{\mathrm{TM}}$, desenvolvida pela empresa Linden Lab: uma mão aberta, com um olho, de igual modo aberto, na palma.

${ }^{24}$ A partir de press release do evento, disponível para consulta na Web. 10 Fev. 2015. http://acloc-27-silvestrepestana.blogspot.pt/
} 


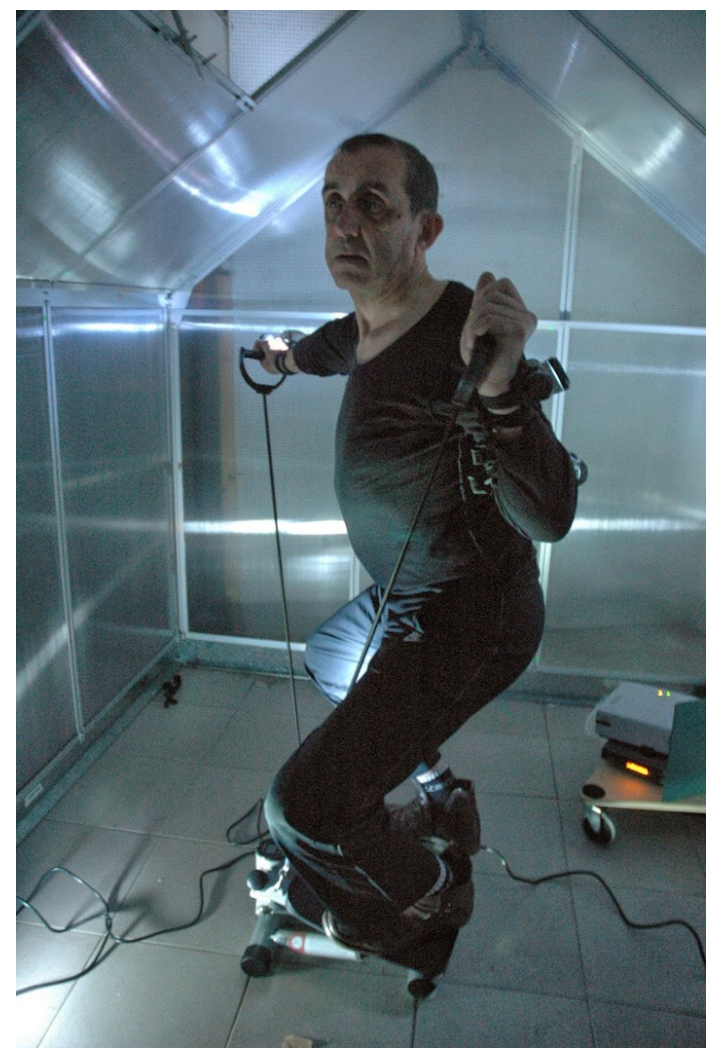

Figura 5. Silvestre Pestana. Galeria Uma Certa Falta de Coerência. Interior de estufa. Cortesia de Silvestre Pestana.

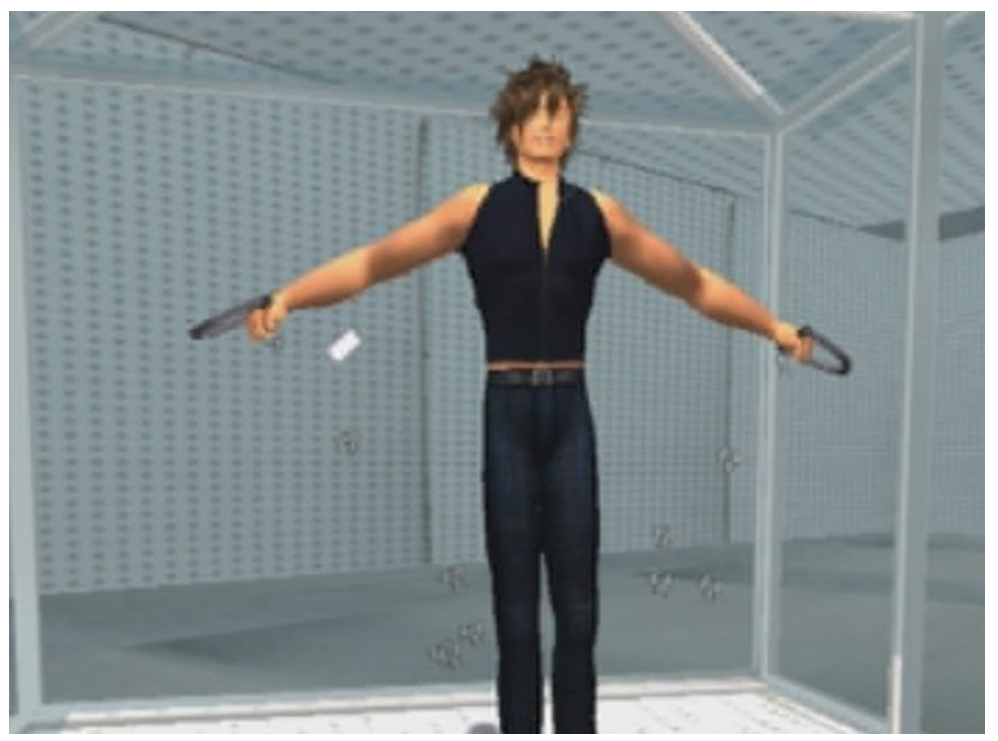

Figura 6. Vitos Flores. Espaço virtual da Galeria Uma Certa Falta de Coerência no SL. Cortesia de Silvestre Pestana. 
E um segundo momento: ACC ÂA FÉNIX 2.0 e Instalaşão, desta feita, a começar em ambiente actual (espaço físico da Galeria Alvarez), para acabar em ambiente virtual. Em ambos os momentos, uma estrutura semelhante, mais concretamente uma estufa, na qual Silvestre Pestana, utilizando uma "stepper", vai pedalando de modo crescente, num tempo limitado ao esgotar das suas forças [Figura 7]. E se na sua "versão 1.0" se dá início a uma reflexão na qual se cruzam dois eus (performer actual e performer virtual), na versão 2.0, o movimento é outro, uma acção - de um eu actual - que se transduz em instalação permanente - de um outro eu virtual. Por outras palavras, esgotada a energia corporal do performer actual, surge em pano de fundo um seu avatar Vitos Flores, pedalando continuamente, sem qualquer sinal de exaustão [Figura 8]. Salientem-se as diferenças entre, por um lado, as características físicas de ambos os performers e, por outro lado, os ambientes actual e virtual: Vitos Flores, de compleição física jovem, pedala num ambiente colorido, luminoso, silencioso, próprio do design standard passível de ser encontrado na referida plataforma virtual, numa emulação da estufa actual, mas própria de um mundo que, aparentemente, não se rege pelas mesmas leis de espaçotempo; Silvestre Pestana, pedalando num ambiente escuro, sinistro, urbano, confinado a quatro paredes, em evidente esforço físico transmitido, sobretudo, pelos esgares de dor que vão aumentando de intensidade.
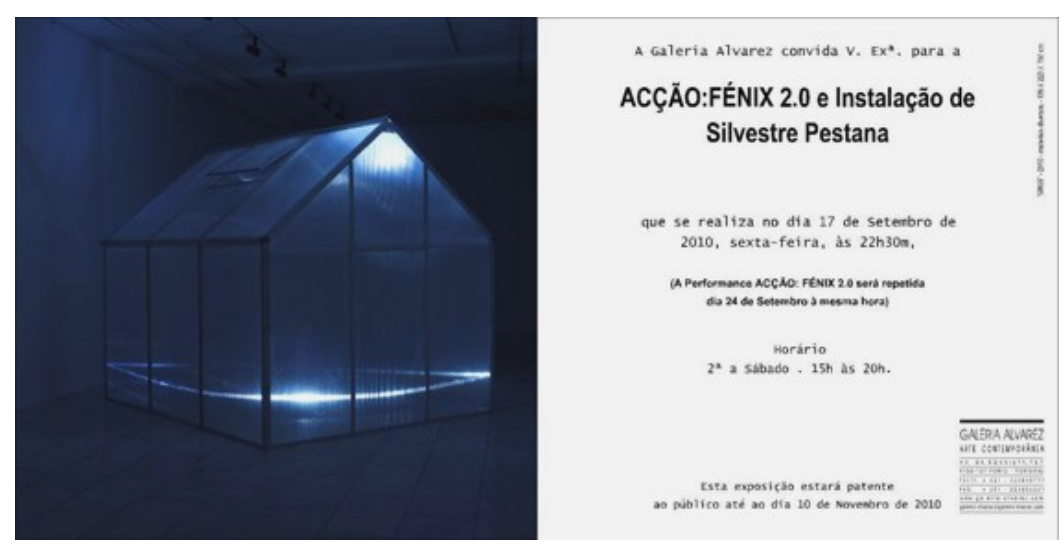

Figura 7. Convite para ACÇ̃A:FÉNIX 2.0 e Instalação. Cortesia de Silvestre Pestana. 


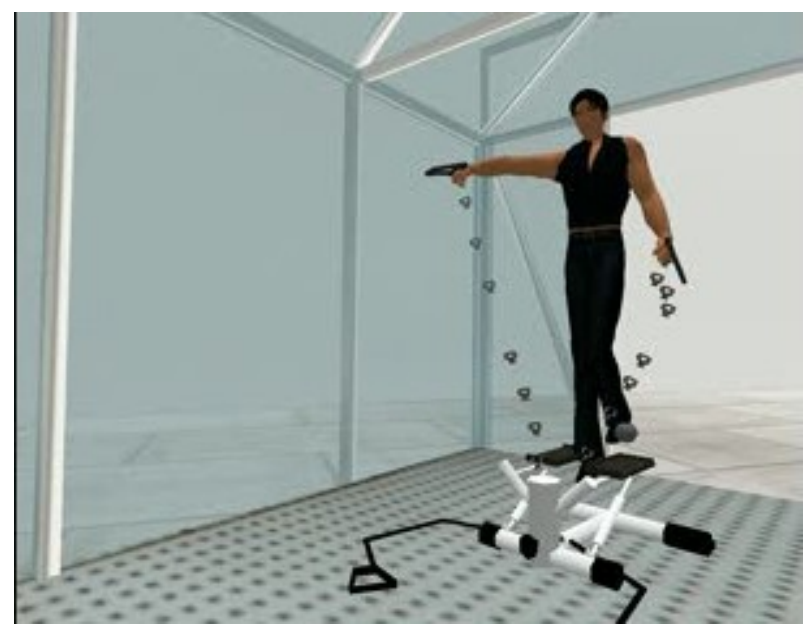

Figura 8. Vitos Flores. FÉNIX 2.0. Cortesia de Silvestre Pestana.

Estes dois caminhos, actual e virtual, que se cruzam momentaneamente no tempo e no espaço - e que não excluem um terceiro passível de ser realizado pelos visitantes, ao permitir, através da interacção com um joysticke, a deambulação pelo espaço virtual da galeria alojado no SL - representam, desta forma, diversas instâncias de contacto. Primeiro, um contacto, num processo de transição e transdução, ${ }^{25}$ entre um eu actual e um eu virtual que (se) afectam e se auto-afectam, no sentido em que, quando o primeiro atinge o limite (o seu possível ponto de contacto), despoleta-se o segundo, num gesto que passa a ser contínuo (pedalar na stepper virtual), mas paradoxalmente interrompido, contaminado, ou, se quisermos, mediado pela máquina. ${ }^{26}$ Em segundo lugar, um contacto entre potência e acto, que Manaíra Athayde

25 Seguimos Massumi, na utilização das palavras "transição" e "transdução" no contexto da noção de "afecto". A primeira, desenhada a partir de Espinoza na sua definição de corpo enquanto "relações de movimento e repouso". Ver Massumi, 2002: 15. A segunda, na descrição de um corpo enquanto transdutor (a propósito de uma performance de Stelarc): "The transducing of the body is extended beyond the skin to propagate through the surrounding space. The transductive physicality of the body extends to the limits of its spatial containment." Ver Massumi, 2002: 104.

${ }^{26}$ A noção de "natural-born cyborgs" é, neste ponto, particularmente útil, por auxiliar na clarificação de processos intermediais entre humano e máquina. Brian Rotman é um dos investigadores que a recupera, nomeadamente na obra Becoming Beside Ourselves: "Reflecting on the relation between the human and the machine, the cognitive theorist Andy Clark urges We shall be cyborgs not in the merely superficial sense of combining flesh and wires, but in the more profound sense of being humantechnology symbionts: thinking and reasoning systems whose minds and selves are spread across biological brain and nonbiological circuitry $(2006,1)$ '. Human beings are "natural born cyborgs"; the 'human' has from the beginning of the species been a three-way hybrid, a bio-cultural-technological amalgam: the 'human mind' - its subjectivities, affects, agency, and forms of consciousness - having been put into form by a succession of physical and cognitive technologies at its disposal". Ver Rotman, 2008: 1. 
descreve enquanto "(dis)tensão entre a potência - as possibilidades do ser, aquilo que ainda não é mas pode vir a ser - e o ato, a ação - a manifestação atual do ser, aquilo que já existe -, numa discussão ontológica que é maquinada sob uma perspetiva sociologizada [...]. Daí ser tão caro ao artista elementos como o útero, a estufa, o aquário e, claro, o ovo." (Athayde, 2013: Ф22). ${ }^{27}$ Mas ainda, um contacto entre "povos", noção igualmente cara a Pestana, o "novo povo novo" que nasce do radical "ovo", 28 e que surge agora representado pelo virtual e pelo avatar, em tudo idêntico a uma ideia de nascimento, à problemática de sobrevivência da espécie (o desejo de uma tangibilidade intangível na busca utópica de imortalidade e na ânsia de um conhecimento imediato?). Em suma, contactos que permitem pensar a noção de "háptico", precisamente pelo entrecruzar de corpos que o seu cenário de Dorian Gray contemporâneo representa (ainda que com uma clara inversão de papéis), mesmo quando o corpo é também um outro, "uma autorenderização", como refere Pestana.

Uma última ave, neste já longo voo (circular, migratório), não de uma outra fénix - que poderia igualmente ser encontrada no autor que se avizinha ${ }^{29}$ - mas de uma outra ave, também ela rara, desta feita pela mão de Eduardo Kac. Rara Avis (1996), performance-instalação que faz uso do com-

${ }^{27}$ A este respeito, ver ainda entrevista com Silvestre Pestana, conduzida pela investigadora Manaíra Athaíde, no âmbito da exposição "Novo Povo Virtual" (Casa da Escrita, Coimbra, 2013). 19 Abr 2015.

https://matlit.wordpress.com/2013/03/22/do-inicio-dos-meios-e-do-fim-em-

silvestre-pestana/

${ }^{28}$ Para além das múltiplas representações do palíndromo "OVO" levadas a cabo pelos vários experimentalismos da segunda metade do século $\mathrm{XX}$, nomeadamente, pelo grupo de poesia concreta brasileira Noigandres, destaca-se ainda a sua particular utilização por vários artistas conotados com o movimento de poesia experimental portuguesa, PO.EX, numa frequente associação com as palavra "POVO" e/ou "NOVO". Por exemplo, António Aragão, com a obra de poesia espacial "POVO/OVO" (1977) e o próprio Silvestre Pestana, com "POEMA /OVO" (1977) e posteriormente, nos anos 80, com Computer Poetry, uma série de poemas para ZX81, ZX82 e Spectrum, obra considerada por diversos investigadores como pioneira na área da literatura electrónica. Cf. Funkhouser, 2007.

${ }^{29}$ Falamos aqui do holopoema Phoenix (1989), da autoria de Eduardo Kac, obra produzida no contexto de uma dupla (e)migração: a primeira obra de Kac em Chicago, EUA, e os processos de experimentação de uma técnica inovadora, a holografia, na confluência com a poesia visual. Obra que Kac descreve do seguinte modo: "[A] poem composed of only one letter that draws attention to its visual properties instead of representing a particular sound. Designed with ambiguity, the letter W might be perceived as a stylized bird with open wings. It floats in front of the holographic film plane (twenty inches away from it) and is transfixed by a vertical open flame that can be read as the letter I and which moves randomly according to air currents. The laser transmission letter-image produces a curious harmony with the actual flame, suggesting perhaps that we are as fascinated by laser images today as the primeval man was by fire. Where the laser red meets the blue flame, a hybrid magenta is perceived". Ver Kac 2007: 142. 
plexo e polémico fenómeno de "telepresença", ${ }^{30}$ para dar origem a uma metarreflexão sobre "a noção problemática de "exotismo", "um conceito que revela mais sobre a relatividade dos contextos e a consciência limitada do observador do que sobre o status cultural do objecto que é observado" (Kac, 1996: \21).

Nesta, os participantes, com acesso remoto via computador (virtual) ou acesso imediato via espaço físico da galeria (actual), podiam experienciar, de duas formas distintas, o espaço de um aviário com cerca de 30 aves, partindo da perspectiva de uma arara telerobótica. Assim, enquanto o participante actual (PA), através de um dispositivo especial visual e aural com capacidade de detetar movimentos da cabeça, era "teletransportado" para o interior do aviário, adoptando a perspectiva da arara, até então imóvel, o participante virtual (PV) partilhava uma visão mediada pelos movimentos do primeiro. Por outras palavras, dois tipos de participantes repercutidos em duas dimensões distintas de virtualidade: uma primeira, iniciada a partir do momento em que o PA mudava a perspectiva da sua visão do aviário, incorporando a arara telerobótica, num movimento de fora para dentro; a segunda, gerada pelo $\mathrm{PV}$, que adoptava de igual modo a perspectiva da arara, mas com a particularidade de uma experienciação via Internet influenciada pelos diferentes arrastamentos de imagem dependentes do hardware e software de cada terminal de acesso. ${ }^{31}$ Adicionando-se o facto de aos últimos ser permitida a utilização de microfones para ativar o dispositivo vocal do telerobô, que assim se fazia

\footnotetext{
${ }^{30}$ A origem da discussão em torno do termo "telepresença" data de 1980, com a publicação de um artigo de Marvin Minsky na área da telerobótica, razão pela qual o termo passou a ser utilizado sempre que se pretendia aludir a uma sensação de estar presente num ambiente virtual digital. Porém, em 1992, o primeiro número da revista Presence (The MIT Press) vem relançar a discussão, apresentando dois artigos com opiniões antagónicas sobre a definição do termo. Num deles, Thomas Sheridan apela à restrição do termo ao campo exclusivo das teleoperações, sugerindo a noção de "presença virtual" sempre que se pretendesse falar de presença em ambientes virtuais. Mas num outro artigo, Richard Held e Nathaniel Durlach defendem a ideia de que o termo "presença" é passível de encaixar em ambas as situações apontadas por Sheridan. Talvez por essa razão, e segundo Gordon Calleja, o termo "presença" tenha vindo a ser utilizado com maior frequência, em detrimento de outros, quer para descrever ambientes virtuais quer físicos (2014: 224). O mesmo Calleja veio posteriormente reacender a polémica, questionando os conceitos de "presença" e de "imersão", com referência aos ambientes virtuais, propondo um outro termo, "incorporação", e por ele descrito como "um fenómeno experiencial que engloba a assimilação simultânea do mundo virtual pela consciência $e$ o reconhecimento sistémico da localização do jogador e a sua existência nele" (2014: 222-223). Mas a discussão terminológica não termina por aqui, existindo várias outras perspectivas interessantes de substituição dos termos algo puídos de imersão e presença, como, por exemplo, "presença mediada" (ver Bracken \& Skalski, apud Waterworth, 2010: 589) ou "corporização distribuída" (ver Waterworth \& Waterworth, 2014: 589-601).

${ }^{31}$ Estas diferentes experiências no acesso à obra, dependentes do equipamento de cada participante remoto, segundo Kac, constituem-se como um reflexo do "ambiente altamente ecológico em que vivemos - modulando e definindo a nossa percepção de realidade" (Kac, 1996).
} 
escutar pelo espaço da galeria. Deste modo, os sons de humanos e de aves viajavam e entrecruzavam-se num processo de retroalimentação contínua entre o espaço da galeria e cada uma das máquinas ligadas remotamente, dando origem a um registo cacofónico crescente e a uma afectação paralela de ecologias (a do aviário actual e a da Internet) [Figuras 9 e 10]. Pegando nas palavras de Kac, pela possibilidade de presença virtual e física em dois lugares ao mesmo tempo, a instalação dava origem a "uma metáfora que permite $\mathrm{o}$ desaparecimento de fronteiras ao mesmo tempo que as reforça", paradoxo que sugere temas de identidade e alteridade, projectando o espectador no interior do corpo de uma ave rara que não só se fazia apresentar como a única da sua espécie no aviário, como também enquanto espécie singular em tamanho, cor e comportamento (idem).

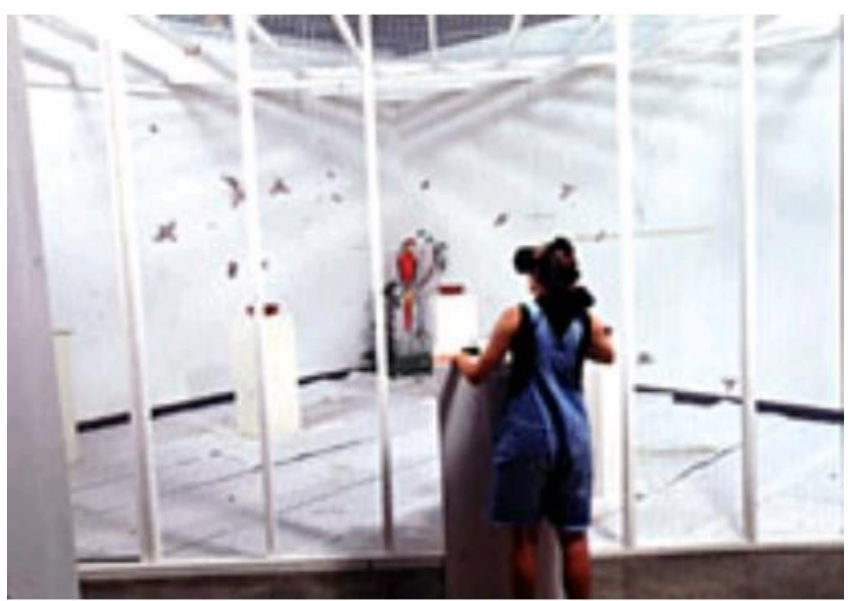

Figura 9. Rara Avis. Perspetiva do exterior da jaula. (C) Eduardo Kac.

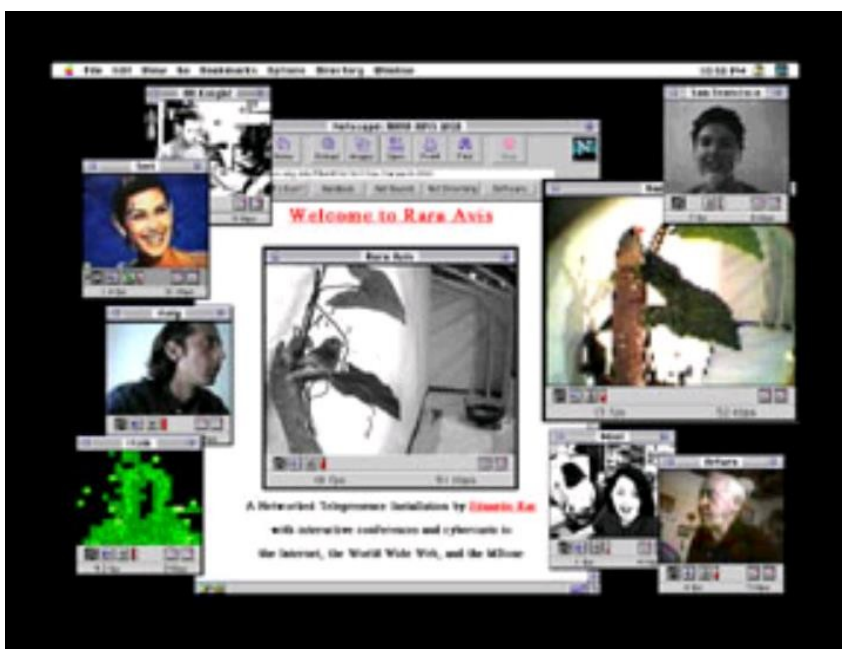

Figura 10.Rara Avis. Página web apresentando conferências interactivas e cybercasts, a partir dos softwares CU-SeeMe e MBone. (C) Eduardo Kac. 
Portanto, falamos de fluxos e ciclos (e)migratórios, tropos centrais em grande parte da obra de Eduardo Kac. É Stephanie Strickland que o aponta, numa análise a Time Capsule, obra de 1997 que envolve, uma vez mais, arte digital e telepresença, mas ainda uma dupla dinâmica, (e)migratória e circular. Nela, Strickland começa por referir o facto de a família de Kac ter chegado ao Brasil nos movimentos migratórios do Leste da Europa para a América do Sul, no final dos anos $30^{32}$, bem como a ida do próprio Kac para Chicago, EUA (2007: 41). E continua a sua análise, descrevendo, por um lado, a complexidade das transições entre analógico e digital ${ }^{33}$ evidenciadas pela performance de Kac bem como, por outro lado, as "microflutuações" que estão por detrás das referidas transições:

Time Capsule takes place in Chicago, Brazil, Poland, the airwaves, the phone lines, around the world on the Web, and in Kac's flesh wherever he goes, yet is called site-specific. It takes place on 11, 12, 13 November, or now on his webpage devoted to it, or always, in his leg, or in the thirties in Poland. It is a body, a broadcast, a netcast, a database, an identification, a schedule, a sound byte, an implant, a webscan, an X-ray, a gallery show. [...] A man is marking his ankle with an identification number under the photographed eyes of his refugee family, a family in flight from a regime that wrote numbers on skin with needles. Without being bound to any machine he is now always readable by a machine, wearing an electronic anklet that monitors him as much as any prisoner. (42)

Neste sentido, à semelhança de Time Capsule e de tantas outras obras suas, Rara Avis parte do mesmo princípio evolutivo que entrecruza tecnologia e arte. Não significando isto que a tecnologia seja aqui mais uma ferramenta ao serviço do processo criativo (e vice-versa). Antes, apenas pela sua assimilação e integração enquanto parte igual de um processo simbiótico aberto e

\footnotetext{
${ }^{32}$ São vários os momentos em que Eduardo Kac, em entrevistas, artigos e obras, faz referência à figura da sua avó, que se viu forçada a viajar da Polónia para o Brasil em 1939. Neste contexto, a sua origem judaica é outra das temáticas centrais na sua arte. Por exemplo, o holopoema Shema (1989). Ver Kac, 1995: 92; 98; 102.

33 Vale a pena recuperar a acurada descrição de Strickland: "On 11 November 1997, in a room in São Paulo with parquet floors and ornate plaster ceiling, he created an inner room of movable white walls on one of which hang seven sepia-toned photographs his grandmother brought from Poland in 1939 - the actual photographs, he says in a talk given a year later, though in the gallery they are not identified in any way. On the facing wall, as of the next day, he hung a diptych combining an X-ray of his ankle with an enlargement of the registration screen for a Web database used to track lost animals; for, on the prior day, broadcast live both to Brazilian TV and to the Web, Kac had injected his leg with a microchip implant that contained a programmed identification number and that, when scanned, emitted a radio signal. He then put his leg in the scanning device, and his ankle was Web-scanned from Chicago, the scanner button being pushed by a telerobotic finger. Kac then registered himself, as both animal and owner, in a North American pet database, the first human to do so." Ver Strickland, 2007: 41-42.
} 
cíclico entre humano e máquina se torna possível questioná-la e inclusive expandi-la. Em suma, uma metapoeticidade que permeia o processo criativo e à qual a questão da multissensorialidade convocada pela tecnologia digital não fica imune.

\section{"Birds of a flock, fly together"}

Fazendo cumprir o provérbio, torna-se possível encontrar rastos de voo feitos em paralelo por todas estas aves, das mais líricas às mais concretas. Numa espécie de voo circular iniciado pelas aves na janela de Kipling e que termina nas migrações cibernéticas entre continentes de uma Rara Avis telerobótica, surge a constatação de que os gestos e as palavras, de facto, terão mais em comum com o voo das aves do que à primeira vista julgaríamos. Não é, porventura, a visão das aves (sobretudo as de rapina), aquela que lhes permite alcançar, agarrar, controlar, uma presa a curtas longas-distâncias? Não são os seus movimentos bruxuleantes, flutuantes, esvoaçantes emulados hoje pela imagem tecnológica e, a um outro nível, por flickering signifiers? ${ }^{34} \mathrm{E}$ o que dizer do seu sistema de orientação no espaço, verdadeiro motor dos seus fluxos migratórios?

A contemplação das aves no seu habitat natural pode, de facto, esconder um desejo maior de poder controlar uma tecnologia sensorial e locomotora que é própria destas e que as nossas capacidades sensoriais "limitadas" não poderão nunca atingir. Mas é nos contactos partilhados entre humano e máquina que esse desejo vai ganhando forma, ainda que esta possibilidade possa assaltar-nos com receios permanentes de uma perda de um domínio conquistado pelo discurso. Razão pela qual concluímos com uma possível solução:

We must get used to being less clever than the artificial brain that we have produced, just as our teeth are less strong than a millstone and our ability to fly negligible compared with that of a jet aircraft. (LeroiGourhan, 1993: 265).

\section{Referências}

AGUIAR, Fernando (1981). O DEDO. Lisboa: Assírio \& Alvim. 19 Abr 2015.

http://po-ex.net/taxonomia/materialidades/planograficas/fernandoaguiar-o-dedo

\footnotetext{
${ }^{34}$ Ver Hayles, 1999: 25-49.
} 
ANGEL, Maria. \& Gibbs, Anna (2013). "At the Time of Writing: Digital Media, Gesture, and Handwriting." Electronic Book Review. 3 Jan. 2015. http://www.electronicbookreview.com/thread/electropoetics/gesture

ATHAYDE, Manaíra Aires (2013). "PO.EX em EXPO (ou POesia EXperimental em EXPOsição): Ernesto Melo e Castro, António Barros e Silvestre Pestana na Casa da Escrita". [Recensão]. MATLIT 1.1 (2013): 193-203. 19 Abr. 2015.

http://iduc.uc.pt/index.php/matlit/article/view/1627/987

BENJAMIN, Walter (2006). "A obra de arte na época da sua possibilidade de reprodução técnica - 3. a versão" [1936]. In Modernidade. Trad. João Barrento. Lisboa: Assírio \& Alvim.

BOOMEN, Marianne van den (2014). Transcoding the Digital: How Metaphors Matter in New Media. Amsterdam: Institute of Network Cultures.

CALLEJA, Gordon (2014). "Immersion in Virtual Worlds". (2014). The Oxford Handbook of Virtuality. Mark Grimshaw (Ed.). New York: Oxford University Press. 222-236.

CRAMER, Florian (2014). "What is Post-Digital?". In Post-Digital Research (aprja), vol 3.1. 19 Abr 2015. http://www.aprja.net/?p=1318

DELEUZE, Gilles \& Félix Guattari (1987). A Thousand Plateaus [1980]. Trans. Brian Massumi. Minneapolis: University of Minnesota Press.

DERRIDA, Jacques (2005). On Touching - Jean-Luc Nancy [2000]. Stanford: Stanford University Press.

DOMINGUES, Diana, \& Suzete Venturelli (2007). "Cibercomunicação Cíbrida no Continuum Virtualidade Aumentada e Realidade Aumentada: era uma vez... a realidade." ARS, 5.10: 108-121.

DUR, Banu İnanç Uyan (2015). "Hand Image as a Metaphor and its Usage in Poster Design." Global Journal of ARTS Humanities and Social Sciences 3.3: 19-28. 22 Abr. 2015.

http://www.eajournals.org/wp-content/uploads/Hand-Image-As-AMetaphor-And-Its-Usage.pdf

ENGBERG, Maria (2013). "Performing Apps Touch and Gesture as Aesthetic Experience." Performance Research: A Journal of the Performing Arts, 18:5, 20-27, DOI: 10.1080/13528165.2013.828932.

FUNKHOUSER, C. T. (2007). Prehistoric Digital Poetry, 1959-1995. Tuscaloosa: University of Alabama Press.

HARAWAY, Donna (1991). “A Cyborg Manifesto: Science, Technology and Socialist-Feminism in the Late Twentieth Century." Donna Haraway. Simians, Cyborgs and Women: The Reinvention of Nature. New York: Routledge. 149-181. 10 Fev. 2015. http://egs.edu/faculty/donnaharaway/articles/donna-haraway-a-cyborg-manifesto/

HATHERLY, Ana (1975). A Reinvenção da Leitura. Lisboa: Editorial Futura.

HAYLES, N. Katherine (2010). Electronic Literature: New Horizons for the Literary. Indiana: University of Notre Dame Press. 
Chicago Press.

(1999). How We Became Posthuman. Chicago: The University of

HUHTAMO, Erkki (2007). "Twin-Touch-Test-Redux: Media Archaeological Approach to Art, Interactivity, and Tactility." Oliver Grau (Ed.) MediaArtHistories. Cambridge, Massachusetts: The MIT Press. 71-102.

JAY, Martin (1993). Downcast Eyes: The Denigration of Vision in Twentieth-century French Thought. Berkeley and Los Angeles: University of California Press.

KAC, Eduardo (2007). "Holopoetry." Eduardo Kac (Ed.). Media Poetry: An International Anthology. Chicago: Intellect Books [1995]. 129-156.

(1996). "Ornitorrinco and Rara Avis: Telepresence Art on the Internet.” Leonardo, 29.5: 389-400. 10 Fev. 2015.

http://www.ekac.org/ornitrara.html

(ed.) (1995). HOLOPOETRY: Essays, Manifestoes, Critical and Theoretical Writings. Lexington, KY: New Media Editions.

KOGONADA (2014). Hands of Bresson. The Criterion Collection. $15 \mathrm{Fev}$ 2015. http://www.criterion.com/current/posts/3196-hands-of-bresson.

LEROI-GOURHAN, André (1993). Gesture and Speech [1964]. Cambridge, Massachusetts: The MIT Press.

MANGEN, Anne (2006). New Narrative Peasures? A Cognitive-phenomenological Study of the Experience of Reading Digital Narrative Fictions. Thesis for the degree doctor artium. Trondheim: Norwegian University of Science and Technology, Faculty of Arts, Department of Art and Media Studies. 19 Abr 2015.

http://ntnu.diva-portal.org/smash/get/diva2:123332/FULLTEXT01.

MARINKOVA, Milena (2011). Michael Ondaatje: Haptic Aesthetics and Micropolitical Writing. London: Continuum Books.

MARKS, Laura (2002). Touch: Sensuous Theory and Multisensory Media. Minneapolis: University of Minnesota Press.

MASSUMI, Brian (2002). Parables for the Virtual: Movement, Affect, Sensation. Durham, NC: Duke University Press.

MCLUHAN, Marshall (2003). "Electronic Revolution: Revolutionary Effects of New Media [1959]." Understanding Me: Lectures and Interviews. S. McLuhan and D. Staines (Eds.). Toronto: McLelland \& Stewart. 1-11.

NANCY, Jean-Luc (1996). "On the Threshold". The Muses, trans.Peggy Kamuf. Stanford: Stanford University Press. (2000). Corpus. Trad. Tomás Maia. Lisboa: Vega. (2008). Noli Me Tangere. On the Raising of the Body. Trans. S. Clift, P.-A. Brault \& M. Naas. New York: Fordham University Press [2003].

NOLAND, Carrie J. (2006). "Digital Gestures." New Media Poetics. Contexts, Technotexts, and Theories. Adalaide Morris \& Thomas Swiss (Eds.). Cambridge, Massachusetts: The MIT Press. 217-244.

ONDAATJE, Michael (1992). The English Patient. London: Bloomsbury.

PATERSON, Mark (2007). The Senses of Touch: Haptics, Affects and Technologies. Oxford: Berg. 
PIROVOLAKIS, Eftichis (2013). "Derrida and Husserl's Phenomenology of Touch: "Inter" as the Uncanny Condition of the Lived Body." Word and Text: a Journal of Literary Studies and Linguistics. 3.2 (December 2013). 99118.

REIS, Pedro (1998). Poesia Concreta: Uma Prática Intersemiótica. Porto: Edições UFP. http://po-ex.net/pdfs/pr-dapoesia.pdf

RYAN, Marie-Laure (2006). Avatars of Story. Minneapolis: University of Minnesota Press.

SILVEIRINHA, Patrícia (2013). Imagem, Corpo, Tecnologia. A Função Háptica das Imagens Tecnológicas. Lisboa. Gulbenkian.

STRICKLAND, Stephanie (2007). "Quantum Poetics: Six Thoughts." Eduardo Kac (Ed.). Media Poetry: An International Anthology. Intellect Books (UCP): Chicago, 25-44.

URIBE, Kirmen (2008). Mientras Tanto Cógeme la Mano. Madrid: Visor Libros. 7-8.

VIEIRA, Flaviano Maciel (2012). Poesia Digital e Tradução Intersemiótica: um olhar sobre producões digitais de Clemente Padin, Joesér Alvarez e Fernando Aguiar. Dissertação de mestrado em Letras. Centro de Ciências Humanas, Letras e Artes - Universidade Federal da Paraíba. João Pessoa. 73-110. 19 Abr 2015.http://bdtd.biblioteca.ufpb.br/tde_busca/arquivo.php?codArquiv $\mathrm{o}=2270$

WATERWORTH, John A. \& Eva L. Waterworth, (2014). "Distributed Embodiment: Real Presence in Virtual Bodies." The Oxford Handbook of Virtuality. Mark Grimshaw (Ed.). New York: Oxford University Press. 589-601. 